\section{On standing and musing}

\author{
Stephen Hancocks OBE
}

Editor-in-Chief
Send your comments to the

Editor-in-Chief,

British Dental Journal

64 Wimpole Street,

London

W1G 8YS

Email bdj@bda.org
The autumn period is usually full of conferences, exhibitions and meetings. This year has proved to be no exception and the $B D J$ team have recently represented the journal by attending the FDI Annual World Dental Congress in Stockholm, the BDTA Showcase at London's ExCel Centre and the American Dental Association's Annual Session in San Antonio. Such occasions as these provide important and valuable opportunities to share thoughts and reactions with existing and potential readers as well as with fellow editors, publishers and dental association staff and officers. Being aware of what is going on in the wider world is no longer merely a pleasant luxury but a necessary imperative.

Pleasingly, the current feedback on the journal and indeed on the suite of publications from the BDA is very positive. With record levels of BDA membership, subscriptions, site licences and online visits the content is arguably being more widely disseminated than ever before, which means a greater and more diverse set of readers with a concomitant set of thoughts and opinions as to what the journal should include and not include. The value of listening to such views is that it informs the decisions we make on the direction, development and shape of the print and online versions of the journal with the obvious objective of continual improvement.

Being present on the stands at the various exhibitions also provides time between encounters for the less frequent activity of standing, staring and musing. As the poem No time to stand and stare by William Henry Davies puts it so reflectively, 'What is this life if, full of care, We have no time to stand and stare?' It is fascinating to see the range of people who are involved in the world of dentistry, the balance of genders in various dental team roles, indeed the number of different team roles and their descriptions. For example, in the USA 'dental assistants' are what we would call dental nurses, one of whom was quite affronted when I used the term dental nurse with the riposte that she was not a nurse as she 'didn't wipe noses and bottoms' and wished to be disassociated from staff who did such things. An interesting interpretation I thought. Also the range of ages, races, sizes and shapes, the diversity of dress sense, demeanour and attitude. The world is certainly changing and patients' expectations of dental professionals are clearly having an effect on this.

\section{ALL DOWN TO MICRO-ORGANISMS}

My staring took me along rows and rows of other stands, corridors of numbered booths, carpeted lengths of exhibition space in a dozen or more halls from which sprung countless suppliers, exhibitors, sales teams and service providers. What fascinated me most was that it was all there, and we were there and every delegate and visitor was there because of the effects of one of the smallest forms of life, the microorganism. All this huge effort, this vast industry, this enormous and complex profession have been created and continue to thrive, variously, because of the activities of organisms that we cannot even see with the naked eye. I accept that it is not an entirely original or particularly profound thought but witnessing so much human endevour in a given place and time all ultimately based on the formation of the newly dubbed 'biofilm' that we previously knew as plaque was rather salutary.

And in between talking to further visitors to the stand I couldn't help but muse further along the 'what if' lines of 'what if someone in the not too distant future managed to solve the problem of plaque formation?' Setting aside for the moment the discussion of just how likely or otherwise such a breakthrough might be, imagine the impact of no further oral disease progression of caries and periodontal disease. Existing damage would still need to be managed but otherwise "new work' would quite disappear. Gone to the point of marginalisation would be the need for matrix bands, scalers, toothbrushes, dental insurance, 'I love my hygienist' stickers, amalgam, composites, appointment books, dentures, surgery wear, burs, gloves, the list is as long as the well trodden byways of booths and stands at any dental exhibition you care to name. It is quite extraordinary that it is virtually all down to plaque but, in the meantime, there's a cavity to detect, a pocket to prevent and a new potential new subscriber to be signed up. Now, where on earth was I?

DOI: $10.1038 /$ sj.bdj.2008.977 